\title{
Composite Motion Design Procedure for Vibration Assisted Small-Hole EDM Using One Voice Coil Motor
}

\author{
Jing Cui ${ }^{1}$ and Zhongyi Chu ${ }^{2}$ \\ ${ }^{1}$ College of Mechanical Engineering and Applied Electronics Technology, Beijing University of Technology, Beijing 100022, China \\ ${ }^{2}$ School of Instrument Science and Opto-Electronics, Beihang University, Beijing 100191, China \\ Correspondence should be addressed to Zhongyi Chu; chuzystar@gmail.com
}

Received 23 June 2015; Revised 23 September 2015; Accepted 4 October 2015

Academic Editor: M. I. Herreros

Copyright (c) $2016 \mathrm{~J}$. Cui and Z. Chu. This is an open access article distributed under the Creative Commons Attribution License, which permits unrestricted use, distribution, and reproduction in any medium, provided the original work is properly cited.

\begin{abstract}
To address the problem of debris accumulation in small-hole electrical discharge machine (EDM) and simplify the design of the spindle head, the paper proposes a novel composite motion design procedure integrated high frequency vibration and large stroke feed using one voice coil motor (VCM). Particularly, for the purposes of high servo accuracy and high frequency response of the composite motion, an improved zero-phase-error tracking controller (ZPETC) algorithm decoupled with the feedback controller is developed for the process control, in which the feedback parameter adjustment is very simple to reduce the computation complexity. At last, the proposed procedure is validated by the experimental study of the established VCM positioning table; the results verify the efficiency of the proposed method.
\end{abstract}

\section{Introduction}

Derived from normal EDM, micro-EDM is one of the most widely used micro manufacturing techniques; it does not make direct contact between the electrode and the workpiece, thus eliminating mechanical stresses and chatter problems during machining $[1,2]$. Micro-EDM is especially devoted to the manufacture of micro components whose sizes range from 1 to $999 \mu \mathrm{m}$ [3]. A small-hole EDM is within the scope of micro-EDM. Small-EDM needs completing feeding process at the same time of removing debris out of the discharge gap [4]. Due to the narrow discharge gap in small-EDM, removing debris is a challenging issue, especially in deep-hole machining and fine finishing with low discharge energy [5].

To overcome the problem of debris accumulation, several approaches have been attempted, such as dielectric fluid flushing and high frequency vibration assistant EDM. But dielectric fluid flushing method is difficult to be applied to small-hole EDM with a very small electrode [6]. In addition ultrasonic actuator is one of the vibration excitation sources of the tool electrode or the workpiece in small-hole drilling processes [7]. The electrode vibration could introduce pulsating flow in the gap which prevents the sticking of debris.
This reduces the instances of arcing and short-circuiting which makes the process much more stable. For example, the effect of electrode jump height on the movement of the debris and fluid flow pattern in deep-hole EDM has been quantified [8]. But the vibration exciter of the ultrasonic device is often manufactured within a narrow frequency range, thereby the vibration frequency is hard to be adjusted. Currently, a vibration platform for small-hole EDM based on voice coil motor (VCM) was developed [9], it is capable of avoiding the easy loss of vibration energy and the heat effect in ultrasonic vibration, and the machining efficiency was significantly improved, compared to the normal smallhole EDM. However, the vibration platform based on VCM makes the workpiece vibrates, rather than the electrode in the machining process, so it is hard to drill the inclined holes. Besides, in the existing processing form, two actuators are usually needed; besides large travel feeding process driven by one actuator, high vibration assistant EDM have to be driven by another actuator to satisfy the requirement of high servo accuracy and high frequency response in the machine process, which increases the complexity of mechanism design and process control. In order to avoid the imperfections of the system, this paper makes significant improvement to 
the existing processing form; large stroke feeding process and high frequency vibration of the tool electrode are driven by one VCM; the composited motion design procedure makes the mechanical structure possible to be utilized in the vibration assisted small-hole EDM.

It is valuable to mention that the working gap of smallhole EDM is extremely narrower than that of the normal EDM [10]. If the amplitude of the electrode is too large, it would lead to a very short circuit and the process is becoming unstable, homologous, if the amplitude is too small; then, it would be very difficult to realize the vibration assisted removing debris. Therefore, to achieve stable machining in large stroke feed, not only higher servo accuracy of motion control but also higher frequency response of the vibration is essential. Many studies have been reported in the development of getting an effective control strategy for EDM process, such as self-tuning adaptive controller [11], fuzzy control [12], and sliding mode control [13]. But these controllers have lots of parameters to be adjusted; this can be a problem for the implementation. It is well known that zerophase-error tracking controller (ZPETC) [14] is an effective solution for precision control; some examples of applying this control strategy to the precision control system can be found in the literature $[15,16]$. However, ZPETC has to act on the reference signal ahead of the closed-loop system; this control architecture leads to two main problems [17]. One is that the feedforward controller may become a rather high-order filter in order to capture all the necessary inverse dynamics of the closed-loop system. The other problem is that the feedforward parameters are dependent on the feedback controller. These severely restrict ZPETC applied in the small-hole EDM process, because the drilling holes have complex machining circumstance and the removing debris is randomly scattered, for each hole processing the feedforward parameters has to be readjusted; that means whenever the user adjusts the feedback parameters, the feedforward parameters need to be recalculated. So how to regulate the ZPECT parameters becomes a practical problem. To overcome this challenge, an improved ZPETC decoupled with the feedback controller for small-hole EDM process is developed in the composite motion design procedure. Herein, ZPETC feedforward controller is designed in front of the plant, rather than the closed-loop system. Thus the feedforward parameters are independent of feedback controller, and ZPETC's implementation and parameters regulation become convenient in small-hole EDM process. The novelty of the work is proposing a composite motion design procedure using one VCM for vibration assisted small-hole EDM and developing an improved ZPETC method which offer an effective control strategy for the process control; particularly, the efficiency of the composite motion procedure is validated through experimental study of the established VCM positioning table.

This paper is organized as follows. Section 2 introduces the overview of the VCM positioning table and the identified model of the VCM positioning table is achieved by the sine sweep method. Then, the improved ZPETC controller is designed in Section 3. In Section 4, a series of macro motion, micro motion, and macro-micro composite motion

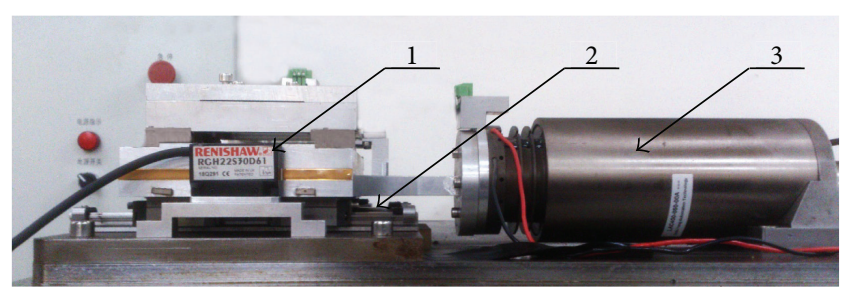

(1) RENISHAW RGH22S grating ruler

(2) A THK super precision ball guide rail

(3) A VCM

Figure 1: The VCM positioning table.

experiments are implemented. The experimental results show the viability of the composite motion design procedure. At last, conclusions and discussion of future work are given in Section 5.

\section{Brief Overview of the VCM Positioning Table}

2.1. Mechanism Structure and System Dynamics. The experimental platform is a voice coil motor- (VCM-) actuating positioning table; the constituents are shown in Figures 1 and 2. Voice coil motor is a direct driving motor that has many advantages such as no cogging effect, fast response, and large thrust. Moreover, it has high movement frequency and can make the tool electrode vibrate at the same time of completing feeding process. VCM's amplifier is TA330-E01 produced by Trust Automation, which can output pure analog quantity with a high resolution ratio and avoid losses in the process of digital switching with distortion near zero. The selected detecting components are the precise raster produced by the company RENISHAW whose resolution is $0.1 \mu \mathrm{m}$. A programmable multiaxes controller (PMAC) clipper with superior performance is selected as the cybernetics core. Using the host computer, the system controls the output of PMAC by means of Ethernet. The output signal drives the VCM to perform the corresponding motions by means of the amplifier and simultaneously, the raster detects the current location information and gives it back to the control card, thus forming a closed-loop control.

2.2. System Dynamics. It is difficult to establish a precise model for the VCM-actuating positioning table using a physically based modeling method for each component of the VCM system; for example, the systematic damping coefficient is very difficult to determine because of the nonlinearity. Therefore, an empirical model for position control is achieved using the system identification technique.

Consider that the frication causes dead zone in the speed response, especially when input voltage has low amplitude and low frequency. So in the system identification, to minimize the effect of frication, sinusoidal signal's amplitudes $300 \mathrm{mV}$, its original frequency $3 \mathrm{~Hz}$, step length $1 \mathrm{~Hz}$, and terminal frequency $10 \mathrm{~Hz}$ are selected to conduct discrete sweep frequency. After the system response is stable, 5000 pieces 


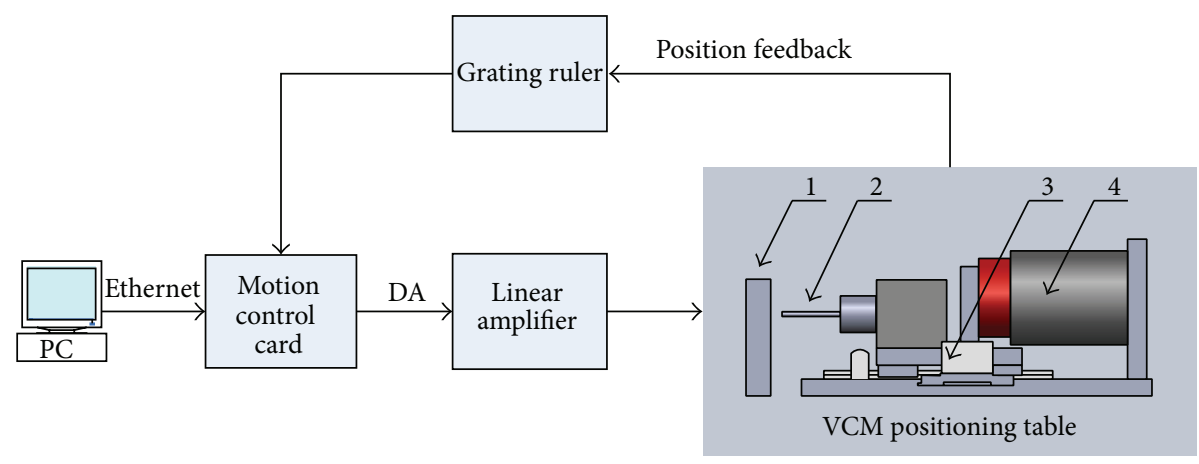

(1) Workpiece $\quad$ (3) RENISHAW RGH22S grating ruler

(2) Electrode (4) A VCM

Figure 2: The VCM system.

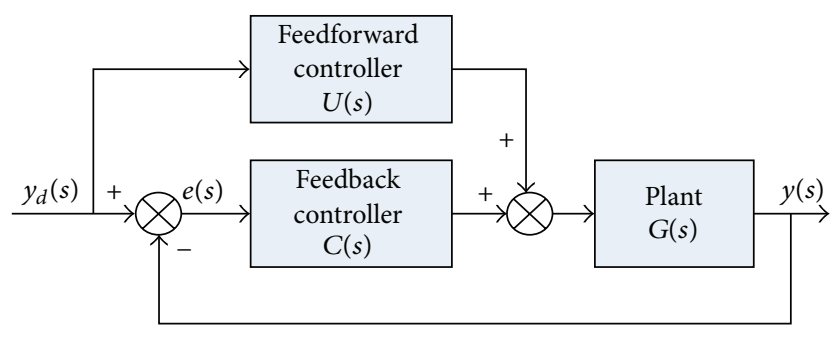

FIgURE 3: The control architectures.

of speed data are, respectively, collected. Finally, the system's frequency characteristic function is achieved by fitting all 5000 points through the least squares algorithm. The transfer function is obtained by the MATLAB function invfreqs (hp,w,a,b), and the identified model for the openloop position control system is obtained as the following:

$$
G(s)=\frac{1432189}{s^{2}+34.6 s} .
$$

Then the discrete model (sampling time is $0.408 \mathrm{~ms}$ ) is achieved as the following:

$$
G(z)=\frac{0.1186 z+0.1181}{z^{2}-1.986 z+0.986} .
$$

From (2), the position model has one unstable zero which is on the negative real axis and close to -1 .

\section{Controller Design}

3.1. The Control Architecture. The improved ZPETC includes two parts: PD feedback controller and the improved ZPETC feedforward loop. The control architecture is as shown in Figure 3. This control architecture makes the ZPETC feedforward controller decoupled with the feedback controller. The specific derivation is as follows.

The error of the system is defined as

$$
e(s)=y_{d}(s)-y(s) .
$$

According to Figure 3, there is

$$
e(s)=\frac{1-U(s) G(s)}{1+C(s) G(s)} y_{d}(s) .
$$

In order to make $e(s)=0$, it should be guaranteed that

$$
1-U(s) G(s)=0 .
$$

Therefore, the feedforward controller is

$$
U(s)=\frac{1}{G(s)} .
$$

From (6) we note that the expression of the feedforward controller is only related to the controlled plant, and it is independent of the feedforward controller. The feedforward compensation loop does not affect the characteristic equation, which means it does not affect the stability of the system. So first adjust the dynamic performance of the system without feedforward compensation to ensure sufficient stability margin and then add the feedforward compensation loop. It is convenient to use this control structure in small-hole EDM process when using an open motion controller, because the feedback controller and the feedforward compensation can be adjusted individually.

3.2. The Improved ZPETC. If the plant can be expressed as

$$
G\left(z^{-1}\right)=\frac{z^{-d} B_{c}^{a}\left(z^{-1}\right) B_{c}^{u}\left(z^{-1}\right)}{A_{c}\left(z^{-1}\right)},
$$

where $z^{-d}$ is $d$ step delay operator, $A_{c}\left(z^{-1}\right)$ is the denominator, $B_{c}^{a}\left(z^{-1}\right)$ is recognized as acceptable polynomial, and $B_{c}^{u}\left(z^{-1}\right)$ is unacceptable polynomial to avoid unstable polezero cancellation.

Then the ZPETC is designed as

$$
u(m)=\frac{A_{c}\left(z^{-1}\right) B_{c}^{u}(z)}{B_{c}^{a}\left(z^{-1}\right) B_{c}^{u}(1)^{2}} y_{d}(m+d),
$$


where $B_{c}^{u}(1)$ in the denominator is a scaling factor to compensate the steady state gain.

As mentioned in Section 2, the discrete function of the plant (2) in this system is

$$
\begin{aligned}
G(z) & =\frac{0.1186 z+0.1181}{z^{2}-1.986 z+0.986} \\
& =\frac{0.1186 z^{-1}\left(0.9953 z^{-1}+1\right)}{0.986 z^{-2}-1.986 z^{-1}+1},
\end{aligned}
$$

where the delay in the plant is $z^{-1}$, stable zero part is $B_{c}^{a}\left(z^{-1}\right)=$ 0.1186 , unstable zero part is $B_{c}^{u}\left(z^{-1}\right)=0.9953 z^{-1}+1$, and $A_{c}\left(z^{-1}\right)=0.986 z^{-2}-1.986 z^{-1}+1$.

The controlled plant zero on the negative real axis and close to -1 may make system highly oscillatory. According to (8), the steady inverse model $u(m)$ can be derived as

$$
\begin{aligned}
& u(m)=\frac{0.986 z^{-3}-1.0046 z^{-2}-0.9767 z^{-1}+0.9953}{0.4723} \\
& \cdot y(m+2) .
\end{aligned}
$$

The corresponding differential equation is

$$
\begin{aligned}
0.4723 u(m)= & 0.986 y(m-1)-1.0046 y(m) \\
& -0.9767 y(m+1)+0.9953 y(m+2) .
\end{aligned}
$$

\section{Experimental Results and Discussions}

According to the survey, several researchers have found that vibration of the tool was more effective in attaining a high material removal rate (MRR) and the machining time is reduced when working under low discharge currents and low pulse times. In general, the surface roughness and the tool wear ratio (TWR) were increased when vibration was employed [18]. Particularly, it was observed that the amplitude and frequency in vibration assisted micro-EDM are the key factor on the machining time, surface roughness, and tool electrode wear. Therefore, this paper is focusing on the experimental study of precise control of hybrid high amplitude/frequency control in feeding process.

In motion test, three experiments are completed. The first one is the macro displacement tracking experiment. One use low frequency and large magnitude sinusoidal signal acts as the macro displacement command signal. This signal simulates electrode large stoke feed in the small-EDM. The second one is the micro displacement tracking experiment. One use high frequency and small magnitude sinusoidal signal acts as the micro displacement command signal. This signal simulates electrode vibrate in the small-EDM. The third one is the macro-micro composite motion experiment. One superpose the macro displacement sinusoidal signal and the micro displacement sinusoidal signal together as the macro-micro composite motion command signal.

The feedback-feedforward control strategy is implemented by PMAC servo loop, where the proportional gain $k_{p}=630$ and derivative gain $k_{d}=300$ as tuning PID value. And the torque offset compensation in PMAC servo loop is used for introducing improved ZPECT feedforward controller.
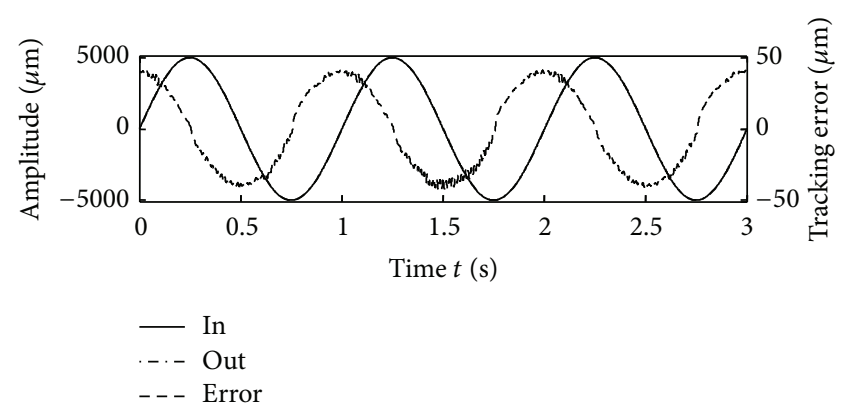

(a)

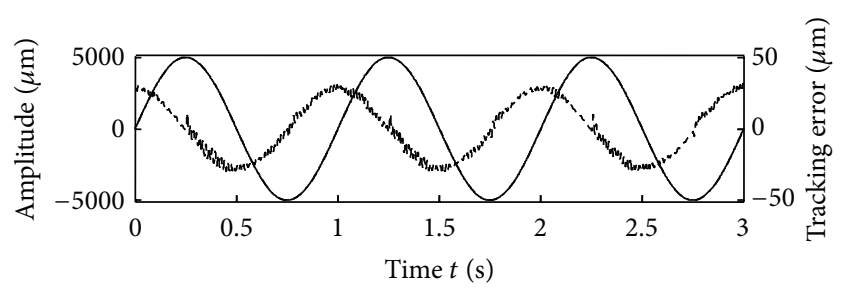

In
$\ldots-$ Out
$\ldots--$ Error

(b)

Figure 4: (a) PID. (b) PID + ZPETC.

4.1. The Macro Displacement Tracking Experiment. Choose sinusoidal signal whose amplitude is $5 \mathrm{~mm}$ and frequency is $1 \mathrm{~Hz}$ to simulate large stroke feed of the electrode movement in micro-EDM. Figure 4 shows the performance comparison of ZPETC controller with PID controller, and the overcut is about $0.23 \mathrm{~mm}$.

As shown in Figure 4(a), the PID tracking error is maximized at the maximum of the velocity, whose value is $40.7 \mu \mathrm{m}$, which is about $0.84 \%$ of the amplitude of input sinusoidal signal.

As shown in Figure 4(b), the improved ZPETC tracking error is maximized at the maximum of the velocity, whose value is $31.1 \mu \mathrm{m}$, which is about $0.62 \%$ of the amplitude of input sinusoidal signal. In addition, the tracking error has a peak when the velocity is across zero, which should be affected by the friction. It has better tracking performance than PID controller.

4.2. The Micro Displacement Tracking Experiment. Choose sinusoidal signal whose amplitude is $30 \mu \mathrm{m}$ and frequency is $50 \mathrm{~Hz} / 100 \mathrm{~Hz}$ to simulate high frequency vibration of the electrode in micro-EDM separately. Figure 5 shows the performance comparison of ZPETC controller with PID controller under $50 \mathrm{~Hz}$. And Figure 6 shows the performance comparison of ZPETC controller with PID controller under $100 \mathrm{~Hz}$, and the overcut is about $16 \mu \mathrm{m}$.

In the micro displacement tracking experiments, because the deviation of amplitude and phase are obvious under high frequency, system response has large tracking error. Under $50 \mathrm{~Hz}$, compared to the input sinusoidal signal, the amplitude of system response increases, so the max tracking error is about $125.6 \%$ of the amplitude of input sinusoidal signal. 


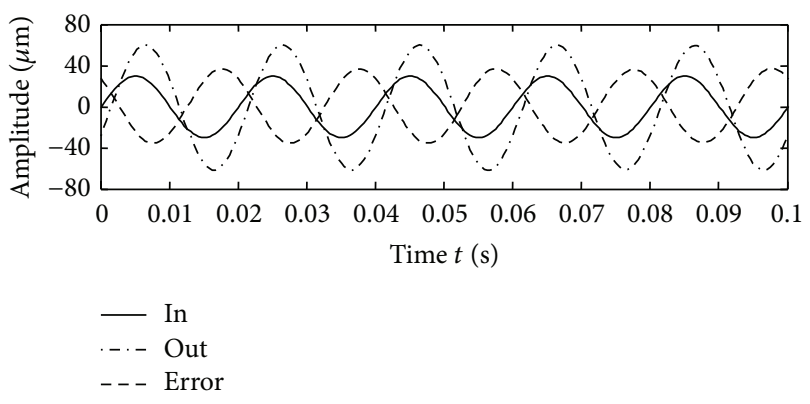

(a)

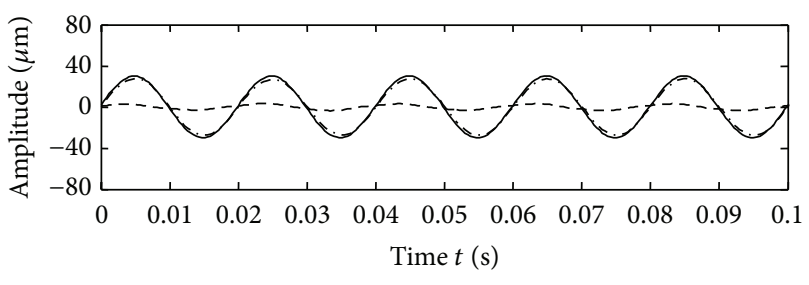

— In

-.. Out

- - - Error

(b)

Figure 5: (a) PID $50 \mathrm{~Hz}$. (b) PID + ZPETC $50 \mathrm{~Hz}$.

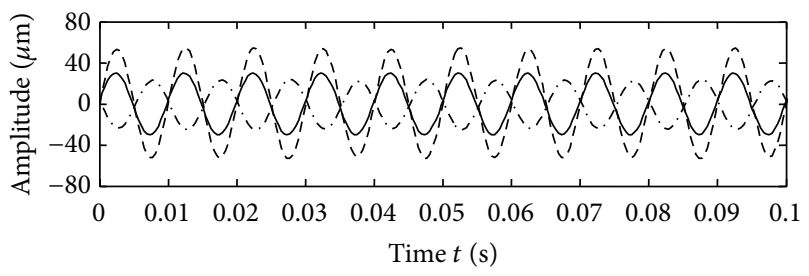

- In

-. Out

- - - Error

(a)

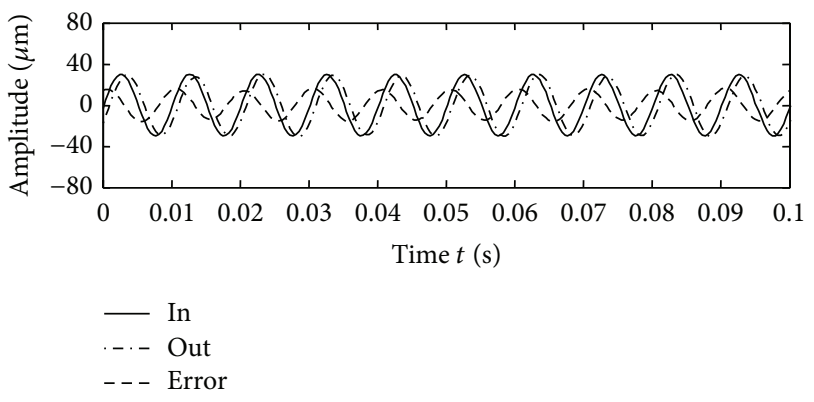

(b)

Figure 6: (a) PID 100 Hz. (b) PID + ZPETC $100 \mathrm{~Hz}$.

At this time the system should be near the inflection point in the closed-loop frequency response. Under $100 \mathrm{~Hz}$, the phase of system response lags almost 180 degrees, so the max tracking error increases to $184.3 \%$ of the amplitude of input sinusoidal signal.

After compensating the feedforward loop, the deviation of amplitude and phase are significantly reduced. Under

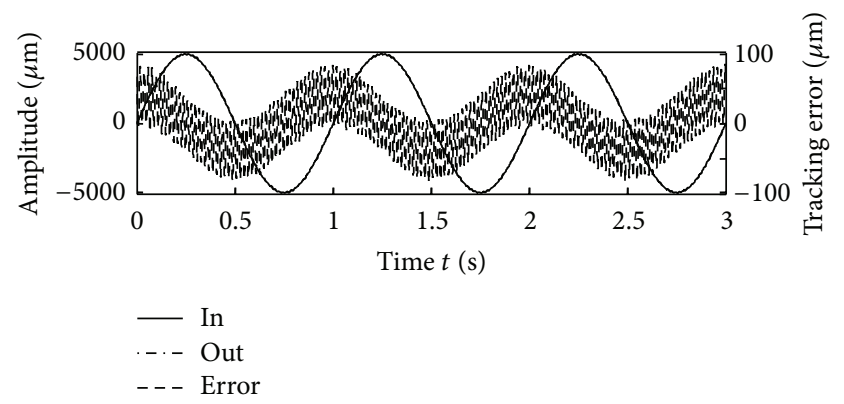

(a)

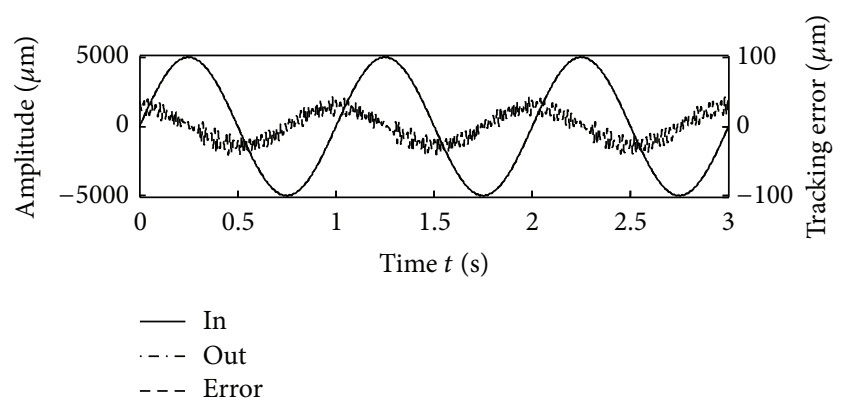

(b)

Figure 7: (a) PID 50 Hz. (b) PID + ZPETC $50 \mathrm{~Hz}$.

$50 \mathrm{~Hz}$, the tracking error mainly manifests as amplitude attenuates; the phase error is almost eliminated. And under $100 \mathrm{~Hz}$, the amplitude error decreases; the tracking error mainly manifests as phase error. However, all the tracking error at high frequency in ZPECT control is further smaller than in PID control. The achievements could be laying the foundation for the future work with implementing small-hole EDM using one voice coil motor.

4.3. The Macro-Micro Composite Motion Experiment. Choose the sinusoidal signal whose amplitude is $5 \mathrm{~mm}$ and frequency is $1 \mathrm{~Hz}$ to combine with the other one whose amplitude is $30 \mu \mathrm{m}$ and frequency is $50 \mathrm{~Hz} / 100 \mathrm{~Hz}$ as servo position command separately. Figure 7 shows the performance comparison of ZPETC controller with PID controller when vibration is $50 \mathrm{~Hz}$. And Figure 8 shows the performance comparison of ZPETC controller with PID controller when vibration is $100 \mathrm{~Hz}$. The initial several cycles are ignored in all the figures.

As shown in Figure 7(a), the PID tracking error is maximized as $83.3 \mu \mathrm{m}$, which is about $1.66 \%$ of the amplitude of input sinusoidal signal. As shown in Figure $7(\mathrm{~b})$, the ZPETC tracking error is $42.4 \mu \mathrm{m}$, which is about $0.84 \%$ of the amplitude of input sinusoidal signal. As shown in Figure 8(a), the PID tracking error is $84.6 \mu \mathrm{m}$, which is about $1.69 \%$ of the amplitude of input sinusoidal signal. As shown in Figure 8(b), the ZPETC tracking error is $42.8 \mu \mathrm{m}$, which is about $0.85 \%$ of the amplitude of input sinusoidal signal.

The tracking error of two signals superposition is about the sum of each tracking error. And comparing Figures 4(b) and 5(b), or comparing Figures 4(b) and 6(b), one can clearly find that the tracking error of the macro displacement is only about $0.62 \%$ of the amplitude of input sinusoidal 


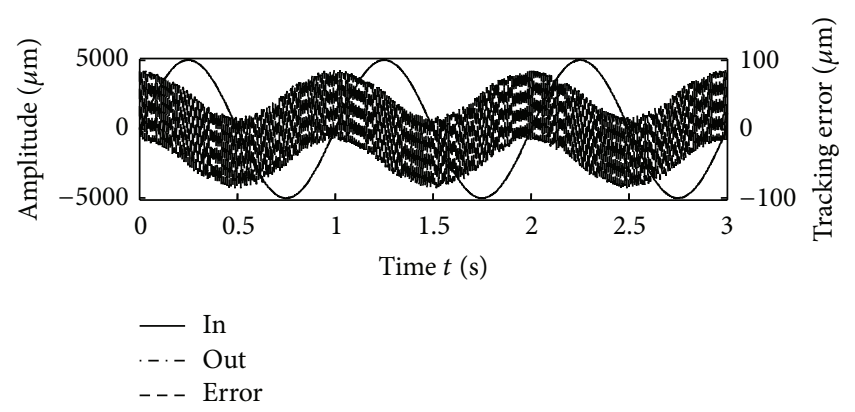

(a)

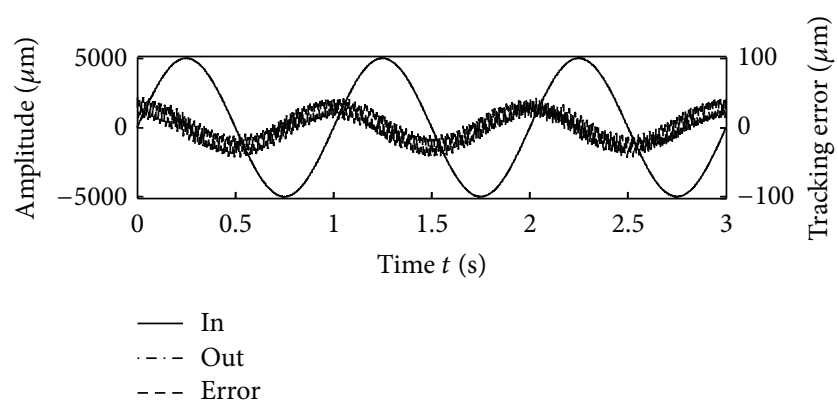

(b)

FIgURe 8: (a) PID 100 Hz. (b) PID + ZPETC $100 \mathrm{~Hz}$.

signal; however, the tracking error of micro displacement is up to $11.9 \%(50 \mathrm{~Hz})$ and $55 \%(100 \mathrm{~Hz})$ of the amplitude of input sinusoidal signal. So according to the proportion of the tracking error induced by macro/micro displacement signals, the tracking error of two signals superposition closely depends on the high frequency tracking performance. When tracking in this kind of movement forms, high frequency response characteristics of the motor should be focused on. Considering that the spark discharge range in the smallhole $\mathrm{EDM}$ is from $10 \mu \mathrm{m}$ to $50 \mu \mathrm{m}$, the tracking error in this study can be accepted. It is shown that good tracking is possible after correction of control algorithm in the VCM servo system.

It is clear that the max tracking error of ZPETC reduces the PID by half in macro-micro composite motion experiments. The results prove the excellent performance and feasibility of the proposed controller which introduces ZPETC to the plant-injection architecture for the small-hole EDM process. In addition, the experiments show that the composite motion integrated high frequency vibration and large stroke feed by one voice coil motor exactly can be achieved.

\section{Conclusions}

(1) To address the problem of debris accumulation in small-hole EDM, this paper proposes a novel composite motion integrated high frequency vibration and large stroke feed by means of VCM position table. This new composite motion can overcome the disadvantages of the traditional mechanical composite where two motions have to be driven separately.
And the feasibility of the composite motion is verified by experimental study.

(2) To achieve higher servo accuracy and higher frequency response in composite motion of VCM position table, an improved ZPECT algorithm is developed for small-hole EDM. This algorithm makes feedforward decoupling from feedback controller; thus ZPETC's design and parameters regulation become easier to implement.

(3) The experimental results of VCM positioning table show the effectiveness of this control strategy and the excellent performance of the composite motion.

Due to the limitation of the PMAC 0.408 ms sampling time, now the highest frequency of assisted vibration is $100 \mathrm{~Hz}$. In the future, we will change or design a different motion control card with shorter sampling time to improve the vibration frequency. In addition, we will design and fabricate a new kind of spindle head. A series of small-hole EDM experiments will be carried out to examine the control performance of composite motion.

\section{Conflict of Interests}

The authors declare that there is no conflict of interests regarding the publication of this paper.

\section{Acknowledgment}

The authors acknowledge the financial support from the Natural Science Foundation of China (51375034, 61005066, and 61327809).

\section{References}

[1] N. M. Abbas, D. G. Solomon, and M. Fuad Bahari, "A review on current research trends in electrical discharge machining (EDM)," International Journal of Machine Tools and Manufacture, vol. 47, no. 7-8, pp. 1214-1228, 2007.

[2] K. H. Ho and S. T. Newman, "State of the art electrical discharge machining (EDM)," International Journal of Machine Tools and Manufacture, vol. 43, no. 13, pp. 1287-1300, 2003.

[3] H. Tong, Y. Li, L. Zhang, and B. Li, "Mechanism design and process control of micro EDM for drilling spray holes of diesel injector nozzles," Precision Engineering, vol. 37, no. 1, pp. 213221, 2013.

[4] J. Wang, F. Han, G. Cheng, and F. Zhao, "Debris and bubble movements during electrical discharge machining," International Journal of Machine Tools and Manufacture, vol. 58, pp. 11-18, 2012.

[5] P. J. Liew, J. Yan, and T. Kuriyagawa, "Fabrication of deep micro-holes in reaction-bonded $\mathrm{SiC}$ by ultrasonic cavitation assisted micro-EDM," International Journal of Machine Tools and Manufacture, vol. 76, pp. 13-20, 2014.

[6] C. Mai, H. Hocheng, and S. Huang, "Advantages of carbon nanotubes in electrical discharge machining," The International Journal of Advanced Manufacturing Technology, vol. 59, no. 1-4, pp. 111-117, 2012. 
[7] G. S. Prihandana, M. Mahardika, M. Hamdi, Y. S. Wong, and K. Mitsui, "Effect of micro-powder suspension and ultrasonic vibration of dielectric fluid in micro-EDM processes-Taguchi approach," International Journal of Machine Tools and Manufacture, vol. 49, no. 12-13, pp. 1035-1041, 2009.

[8] S. Cetin, A. Okada, and Y. Uno, "Effect of debris distribution on wall concavity in deep-hole EDM," JSME International Journal Series C Mechanical Systems, Machine, vol. 47, no. 2, pp. 553-559, 2004.

[9] Y. Jiang, W. S. Zhao, X. M. Kang, and L. Gu, "Vibration assisted EDM of small-hole using voice coil motor," Procedia CIRP, vol. 1, pp. 645-650, 2012.

[10] F. Z. Han, S. Wachi, and M. Kunieda, "Improvement of machining characteristics of micro-EDM using transistor type isopulse generator and servo feed control," Precision Engineering, vol. 28, no. 4, pp. 378-385, 2004.

[11] M. Zhou and F. Z. Han, "Adaptive control for EDM process with a self-tuning regulator," International Journal of Machine Tools and Manufacture, vol. 49, no. 6, pp. 462-469, 2009.

[12] L. Li, Y. Zhang, and Z. W. Niu, "Application of adaptive fuzzy control system in electric discharge machining," in Proceedings of the 3rd International Conference on Modeling and Simulation, pp. 329-332, Wuxi, China, 2010.

[13] M.-T. Yan, "An adaptive control system with self-organizing fuzzy sliding mode control strategy for micro wire-EDM machines," International Journal of Advanced Manufacturing Technology, vol. 50, no. 1-4, pp. 315-328, 2010.

[14] M. Tomizuka, "Zero phase error tracking algorithm for digital control," Journal of Dynamic Systems, Measurement and Control, vol. 190, no. 1, pp. 65-68, 1987.

[15] Y. J. Shin and P. H. Meckl, "Controller design procedure for twomass systems with single flexible mode," Journal of Dynamic Systems, Measurement and Control-Transactions of the ASME, vol. 130, no. 3, Article ID 031002, 2008.

[16] J. A. Butterworth, L. Y. Pao, and D. Y. Abramovitch, "Analysis and comparison of three discrete-time feedforward modelinverse control techniques for nonminimum-phase systems," Mechatronics, vol. 22, no. 5, pp. 577-587, 2012.

[17] J. A. Butterworth, L. Y. Pao, and D. Y. Abramovitch, "A comparison of control architectures for atomic force microscopes," Asian Journal of Control, vol. 11, no. 2, pp. 175-181, 2009.

[18] A. Abdullah and M. R. Shabgard, "Effect of ultrasonic vibration of tool on electrical discharge machining of cemented tungsten carbide (WC-Co)," International Journal of Advanced Manufacturing Technology, vol. 38, no. 11-12, pp. 1137-1147, 2008. 


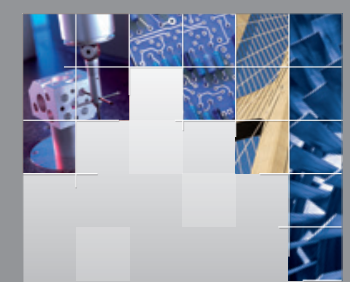

\section{Enfincering}
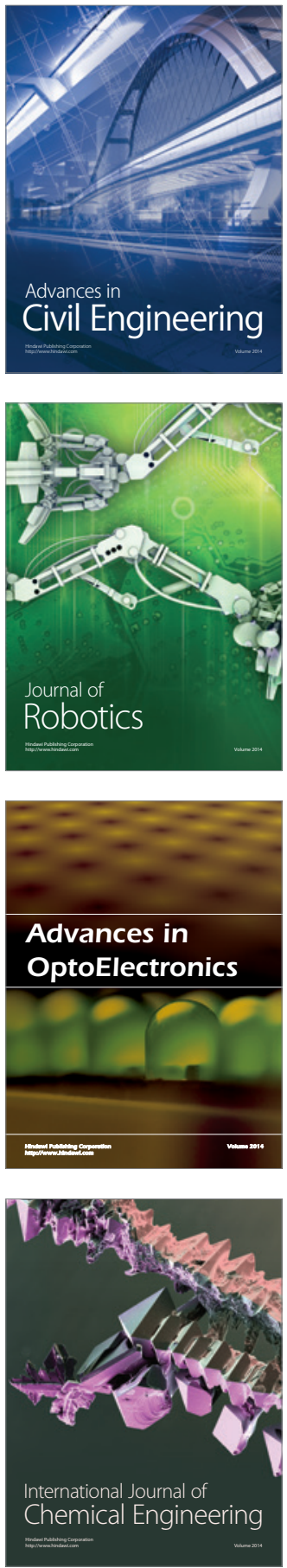

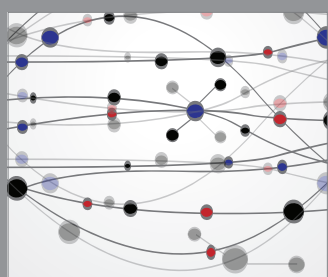

The Scientific World Journal

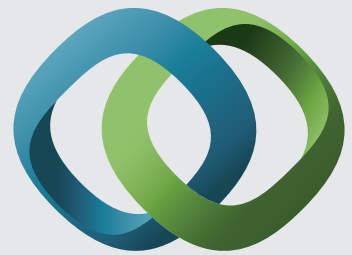

\section{Hindawi}

Submit your manuscripts at

http://www.hindawi.com
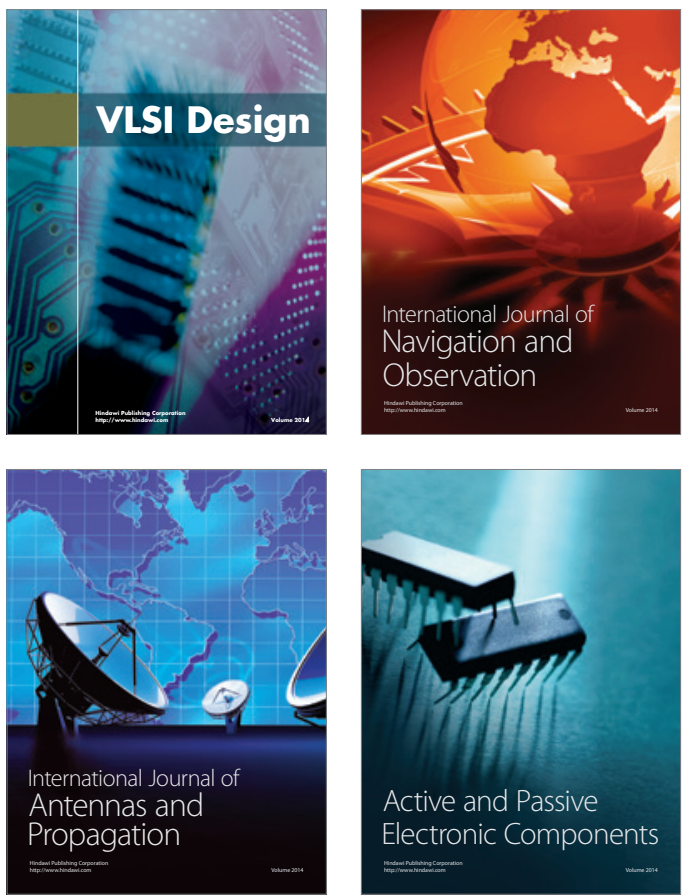
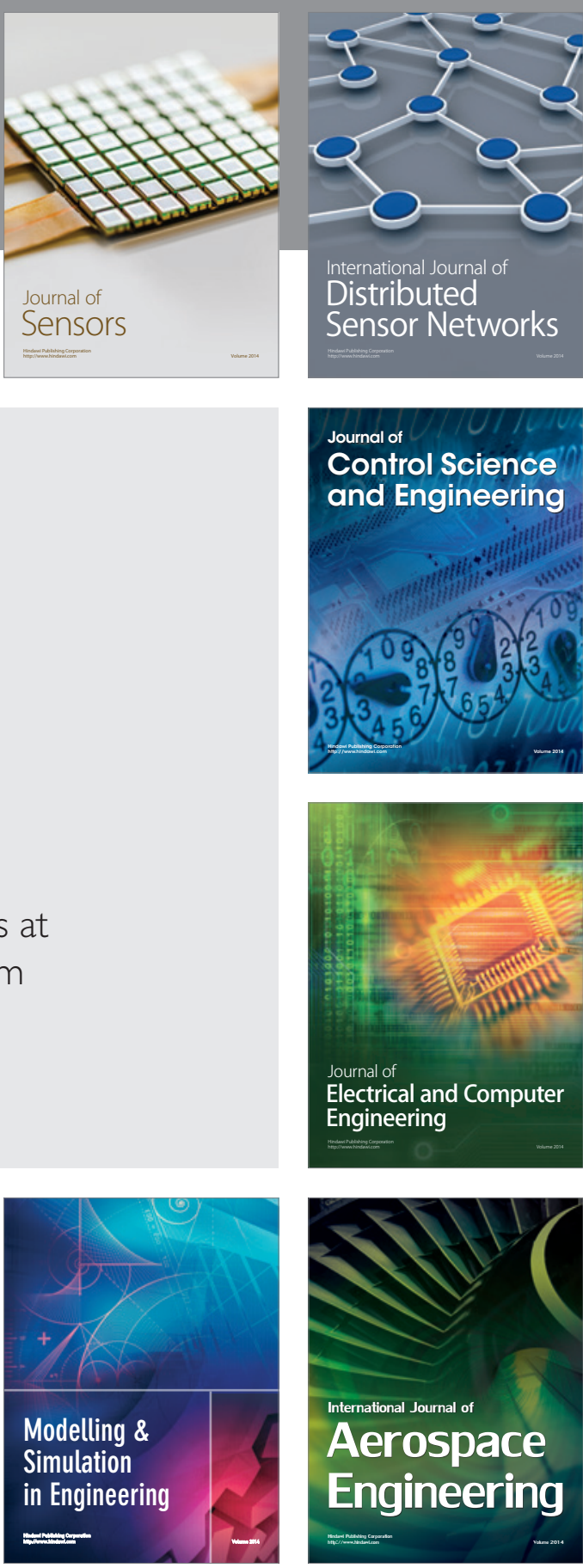

International Journal of

Distributed

Sensor Networks

Journal of

Control Science

and Engineering
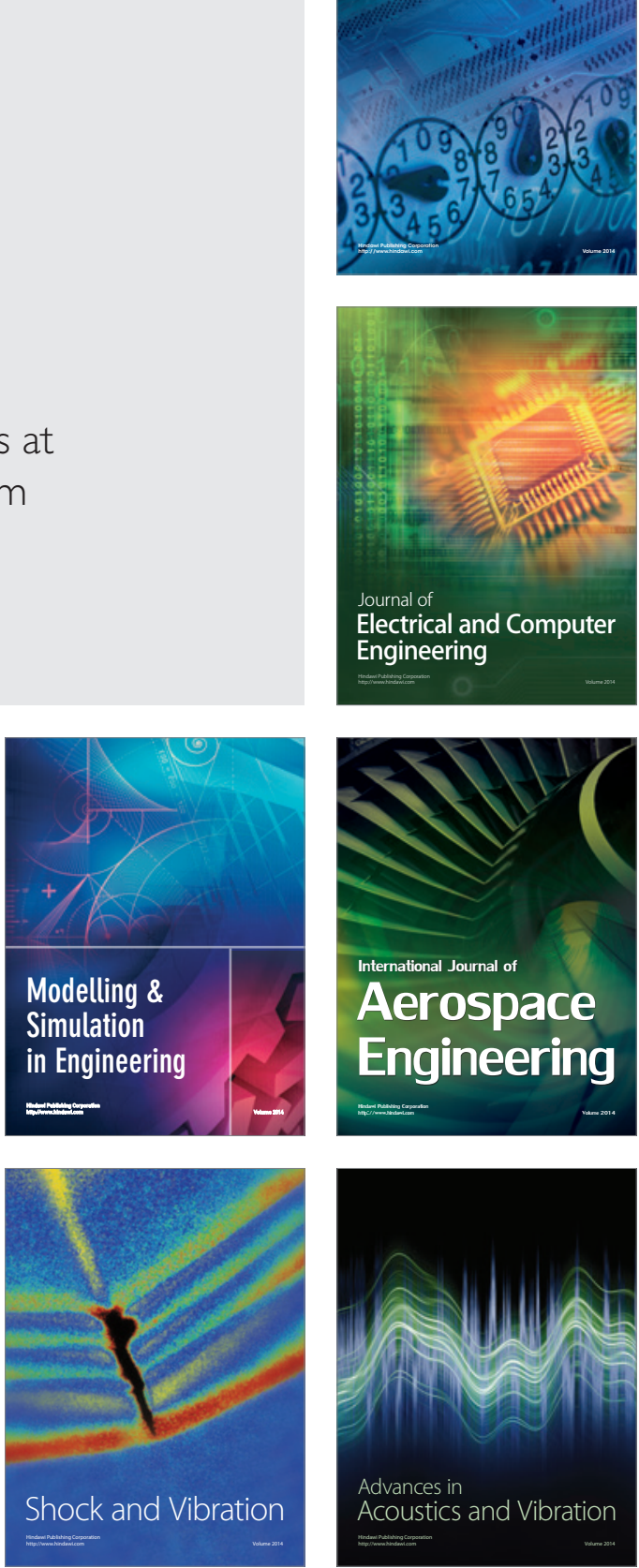